\title{
Comparative studies on microstructures and chemical compositions of cell walls of two solid wood floorings
}

\author{
Yurong Wang ${ }^{1,2}\left(\mathbb{D}^{\circ} \cdot\right.$ Minglei Su$^{1} \cdot$ Haiyan Sun ${ }^{1,2} \cdot$ Haiqing Ren ${ }^{1}$
}

Received: 12 February 2018 / Accepted: 8 June 2018 / Published online: 11 July 2018

(c) The Japan Wood Research Society 2018

\begin{abstract}
Two common wood flooring materials, taun (Pometia spp.) and cumaru (Dipteryx odorata), were used as investigated objects and comparison was made between the two wood species for their density, microstructure, microfibril angle (MFA), cellulose crystallinity and the main chemical composition. Results showed that the density of cumaru was $0.941 \mathrm{~g} \cdot \mathrm{cm}^{-3}$, significantly larger than that of taun, $0.737 \mathrm{~g} \cdot \mathrm{cm}^{-3}$. The biggest difference of two wood species in microstructures was fiber cells. Fiber cells of cumaru had dense cell walls, almost no cell lumens; while fiber cells of taun had relatively thin cell walls, with apparent cell lumens. The thickness of fiber cell wall of cumaru and taun were 6.80 and $2.82 \mu \mathrm{m}$, respectively, and the former is about 2.5 times thicker than the latter. Measured data of MFA indicated that the average MFA of cumaru was $11.7^{\circ}$, smaller than that of taun, $13.4^{\circ}$. The relative crystallinity of cumaru and taun were 54.0 and $50.8 \%$, respectively. The two wood species had the similar holocellulose contents, but the lignin content of cumaru was higher than that of taun, especially that the content of extractive of cumaru was as twice as that of taun.
\end{abstract}

Keywords Solid wood flooring $\cdot$ Microstructure $\cdot$ MFA $\cdot$ Crystallinity $\cdot$ Chemical composition

\section{Introduction}

Solid wood flooring is processed directly from natural woods and it is a kind of green flooring material. In recent years, with the restriction on wood cutting, the total amount of solid wood flooring raw materials is decreasing [1]. How to effectively utilize the existing solid wood flooring timbers and develop new wood species has become a hot topic. The properties of woods are the basis for the development of solid wood flooring and its utilization, while cell wall is a basic element for load performance and modification processing of solid wood flooring, and it is the main structural factor that determines the wood properties. Therefore, studies on the chemical composition and structural characteristic are of great significance.

Yurong Wang

yurwang@caf.ac.cn

1 Research Institute of Wood Industry, Chinese Academy of Forestry, Beijing 100091, People's Republic of China

2 Research Institute of Forestry New Technology, Chinese Academy of Forestry, Beijing 100091, People's Republic of China
At first, Chinese solid wood floorings are mainly made of domestic woods, but with the increasing demands of solid wood flooring, the domestic supply of woods is insufficient. Now more and more imported woods are used as solid wood flooring, among of which, cumaru (Dipteryx odorata) from South America and taun (Pometia spp.) from South East Asia are common wood species of solid wood flooring available in the market. For the two kinds of woods, researches had been carried out mainly on anatomical features [2], physical and mechanical properties [3], shrinking and swelling [4] and dimensional stability [5]. The research showed that the physical and mechanical properties of cumaru woods, which sold at a high price in the market, are better than that of taun woods.

The solid material of woods is cell wall substance, so the macroscopic physical and mechanical properties of woods are mainly related to cell wall properties of woods, such as microfibril angle (MFA), cellulose crystallinity and chemical composition [6-8]. However, most of previous studies mainly investigated physical and mechanical properties of cumaru and taun woods at the macroscopic level and the measures for modification processing of the two kinds of woods. Few studies had been conducted on the microstructures and chemical compositions of cell walls that decide 
the wood flooring properties. There are great differences in macroscopic physical and mechanical properties between cumaru and taun woods.

In this article, we investigated the microstructure, MFA, cellulose crystallinity and chemical composition of the two kinds of woods and revealed the structural features and chemical compositions of cell walls, at the same time, the air-dry density of the two kinds of woods also had been tested for making sure the quantity of solid substances in the cell walls. The purpose of this article was to reveal the structural and chemical characteristics of the cell walls of solid wood floorings, and provided an important scientific theoretical basis for the development, utilization and modification of wood flooring, as well as for the design of composite materials with imitating cell-wall structure.

\section{Materials and methods}

\section{Materials}

Two imported wood species: cumaru and taun were used as investigated objects. The test materials were flooring blanks purchased from Zhejiang Nanxun flooring factory. Test materials were processed into test samples with dimensions of $20 \mathrm{~mm} \times 20 \mathrm{~mm} \times 20 \mathrm{~mm}$ $(\mathrm{R} \times \mathrm{T} \times \mathrm{L})$ and $10 \mathrm{~mm} \times 10 \mathrm{~mm} \times 15 \mathrm{~mm}(\mathrm{R} \times \mathrm{T} \times \mathrm{L})$ and $1.5 \mathrm{~mm} \times 10 \mathrm{~mm} \times 45 \mathrm{~mm}(\mathrm{R} \times \mathrm{T} \times \mathrm{L})$, which were used for measuring air-dry density and microstructure observation as well as MFA. At the same time, the test materials were ground after air-drying, and wood powders with above 60-80 mesh sizes were used for determination of crystallinity and cell wall chemical compositions.

\section{Air-dry density test}

Small samples of the two kinds of woods with the size of $20 \mathrm{~mm} \times 20 \mathrm{~mm} \times 20 \mathrm{~mm}$ were placed in a constant temperature and humidity chamber with the temperature of $20{ }^{\circ} \mathrm{C}$ and humidity of $65 \%$, until the equilibrium moisture content was reached. The dimensions of samples at various directions were measured and the mass of samples were weighed, finally the air-dry density of the two wood species at the moisture content of $12 \%$ was calculated [9]. The 24 samples from each wood species were selected for testing of air-dry density.

\section{Microstructure observation}

The three samples in each species were selected for microstructure observation. The cross-sectional sections with a relatively complete structure can not be directly obtained using a sliding microtome. Therefore, the cumaru and taun samples were softened, respectively. The taun samples were placed in hot water and soaked for 2 days. The cumaru samples were placed in a $3 \%$ ethylenediamine solution for 2 days, and then immersed in hot water for 1 day. After softening, the samples were cut into sections with $16 \mu \mathrm{m}$ thickness using Leica SM2010R sliding microtome, after safranin staining and gradient alcohol dehydration and mounted by Canada balsam, the sections containing a ring were placed under a ZEISS A1 optical microscope and the morphology and distribution of tissue cells of two kinds of solid wood floorings were observed. The double cell wall thickness of cross-sectional fibers of each sample was measured by Axiovision image processing software (Axiovision Release 4.6.3, Carl Zeiss, Germany). The 50 fibers were selected for measurement and the data were analyzed by Excel and SPSS software (SPSS Statistics 19, IBM Company, America).

\section{MFA measurements}

The MFA of the two kinds of woods were determined by X'pert PRO polymorphism X-ray diffractometer made by Dutch PANalytical Company, with 25 samples for each wood species. During testing, samples were placed on the sample tray of X-ray diffractometer, and the tangential section of samples was vertical to the direction of X-ray. The basic parameters of diffractometer included diffraction angle of $22.4^{\circ}$, rotation range of $0^{\circ}-360^{\circ}$, rotation pace of $0.5^{\circ}$, tube voltage of $40 \mathrm{kV}$ and tube current of $40 \mathrm{~mA}$. The diffraction patterns of the 002 surface were obtained after rotation of samples by $360^{\circ}$, and the MFA of samples were calculated by $0.6 \mathrm{~T}$ method, so as to finally obtain the mean MFA of cumaru and taun [10].

\section{Crystallinity determination}

The 5 samples for each wood were chosen. The crystallinity of two woods was determined by X-ray diffractometer (D/max-rB, Rigaku, Japan). When testing, powdery samples were placed in a sample box, and radiated by nickel foil filtered $\mathrm{CuK}_{\alpha}$, with the voltage of radiant tube at $40 \mathrm{kV}$, scanning range of $5^{\circ}-40^{\circ}$, step size at $0.02^{\circ}$ and scanning speed at $4 \% \mathrm{~min}$. After testing, according to the diffraction patterns, the cellulose crystallinity of various samples was calculated by the Segal empirical method. When the maximum integral intensity of the wood fiber diffraction intensity at $2 \theta=22^{\circ}$ was $I_{\mathrm{u}}$ and the minimum integral intensity at the valley of $2 \theta=18^{\circ}$ was $I_{\mathrm{a}}$, then the crystallinity was calculated by the formula $\mathrm{C}_{\mathrm{r}} \mathrm{I}=\left(I_{\mathrm{u}}-I_{\mathrm{a}}\right) / I_{\mathrm{u}} \times 100 \%$, ultimately the mean crystallinity of cumaru and taun was obtained [11]. 


\section{Determination of chemical composition}

The chemical composition contents of wood powder samples of the two woods were determined by conventional national standard method. The wood powder was uniformly mixed from five flooring blanks of each species, and three repeated tests were made for each sample. The main chemical compositions included holocellulose and $\alpha$-cellulose, acid-insoluble lignin and extractive. The contents of all compositions were determined according to Chinese national standards: GB/T 2677.10-1995 Fibrous raw material- Determination of holocellulose [12], GB/T 744-1989 Determination of $\alpha$-cellulose [13], GB/T 2677.8-1994 Determination of acidinsoluble lignin [14], and GB/T 2677.6-1994 Determination of solvent extractive [15], respectively, and finally the mean contents of holocellulose, $\alpha$-cellulose, acid-insoluble lignin and solvent extractive of cumaru and taun woods were obtained.

\section{Results and discussion}

\section{Air-dry density analysis}

Cumaru and taun woods are the preferred flooring materials and commonly available in the markets. The price of cumaru wood is much higher than that of taun wood. In addition to the difference in appearance of the two kinds of woods, the weight between them varies greatly, and the weight of cumaru wood is greater than that of taun wood. The density determines the weight of wood. The air-dry density of the two kinds of woods was measured. The results are shown in Table 1 . The mean air-dry density of cumaru and taun was 0.941 and $0.737 \mathrm{~g} \cdot \mathrm{cm}^{-3}$, respectively. The air-dry density of cumaru wood was significantly higher than that of taun wood and the one-way analysis of variance showed that the difference in air-dry density between the two kinds of woods was statically significantly different, as shown in Table 2 .
Table 1 The mean values and deviations of density, MFA and crystallinity of cumaru and taun woods

\begin{tabular}{lllcc}
\hline Wood species & $\begin{array}{l}\text { Air-dry density/ } \\
\mathrm{g} \cdot \mathrm{cm}^{-3}\end{array}$ & $\begin{array}{l}\text { Fiber thickness/ } \\
\mu \mathrm{m}\end{array}$ & MFA ${ }^{\circ}{ }^{\circ}$ & Crystallinity/\% \\
\hline $\begin{array}{llll}\text { cumaru } \\
\text { Mean value }\end{array}$ & 0.941 & 6.80 & 11.7 & 54.0 \\
$\quad$ Standard deviation & 0.051 & 1.31 & 0.622 & 0.01 \\
Coefficient of variation/\% & 5.47 & 0.193 & 5.32 & 1.78 \\
taun & & & & \\
Mean value & 0.737 & 2.82 & 13.4 & 50.8 \\
Standard deviation & 0.035 & 0.349 & 1.16 & 0.014 \\
Coefficient of variation/\% & 4.71 & 0.125 & 8.66 & 2.84 \\
\hline
\end{tabular}

${ }^{\text {a Microfibril angle }}$

\begin{tabular}{llrllll}
\hline Impact factor & Deviation resource & $\begin{array}{l}\text { Degree of } \\
\text { freedom }\end{array}$ & $\begin{array}{l}\text { Sum of } \\
\text { deviation } \\
\text { square }\end{array}$ & $\begin{array}{l}\text { Mean sum } \\
\text { of square }\end{array}$ & $F$ & $F 0.05$ \\
\hline Air-dry density & Inter-group & 1 & 0.346 & 0.346 & 17.6 & 4.04 \\
& Intra-group & 47 & 0.943 & 0.020 & & \\
& Total & 48 & 1.29 & & & \\
Thickness of fiber cell wall & Inter-group & 1 & 400 & 400 & 431 & 3.94 \\
& Intra-group & 99 & 91.8 & 0.927 & & \\
& Total & 100 & 491 & & & \\
MFA & Inter-group & 1 & 34.8 & 34.8 & 44.8 & 4.04 \\
& Intra-group & 49 & 38.1 & 0.777 & & \\
Crystallinity & Total & 50 & 72.9 & & & \\
& Inter-group & 1 & 45.4 & 45.4 & 37.8 & 5.32 \\
& Intra-group & 9 & 9.61 & 1.20 & & \\
\hline & Total & 10 & 55.0 & & & \\
\hline
\end{tabular}

${ }^{\mathrm{a}}$ Microfibril angle
Table 2 The variance analysis of density, MFA and crystallinity of cumaru and taun woods 
Wood density is a major factor for the evaluation of wood quality [16]. In general, woods of high density have more cell wall substances and better physical properties and mechanical strength. Wang et al. found that shrinkage rate of volume (8.46\%), static bending (144 MPa), and modulus of elasticity of bending (19.0 GPa) of camura were superior than that $(10.6 \%, 125 \mathrm{MPa}, 16.5 \mathrm{GPa})$ of taun [3]. Cumaru wood flooring has a high density and is one of important reasons why it has better physical and mechanical properties and a higher price in market than taun wood flooring.

\section{Microstructure analysis}

Before observing microstructures of cumaru and taun flooring woods, we observed the appearance of the two kinds of solid wood floorings. It was found that the surface textures of the two kinds of woods were different, and the cumaru solid wood flooring which sell at higher price, had a dense surface, with beautiful patterns like dragon and phoenix, so it is called as Freijo. The surface of the taun solid wood flooring had no obvious patterns and its surface color was not uniform, as shown in Fig. 1. The surface morphology of solid wood flooring is determined by its microstructure characteristics. Therefore, observation was done toward the microstructures of the two kinds of solid wood floorings.

The cross-sectional microstructure images from middle parts in a ring, early wood parts, of cumaru and taun woods were obtained by conventional section method, as shown in Fig. 2.Their vessel morphology was not different, dominated by solitary pores and containing a small number of multiple pores. The axial parenchymas of cumaru take on appearances of aliform shape, confluent shape and terminal shape, while that of taun is uniform distribution around their vessels. The biggest difference in microstructures between the two woods existed in their fiber cells. As shown from the enlarged figures $b$ and $d$ in Fig. 2, the fibers of cumaru had thick wall and small lumen, and the whole cell showed dense cell wall, almost no cell lumen. Comparing with cumaru, fiber cells from taun wood had larger lumen and thinner wall, and cell lumens could be seen obviously (Fig. 2, d).

By measuring the wall thickness of fiber cells of the two solid wood floorings, $6.80 \mu \mathrm{m}$ was obtained for the mean single wall thickness of cumaru fiber cells, while $2.82 \mu \mathrm{m}$ was discovered for the mean single wall thickness of taun, as shown in Table 1. The thickness of the former was about 2.5 times of that of later. The analysis on the microstructures of the two solid wood floorings revealed that the cumaru wood

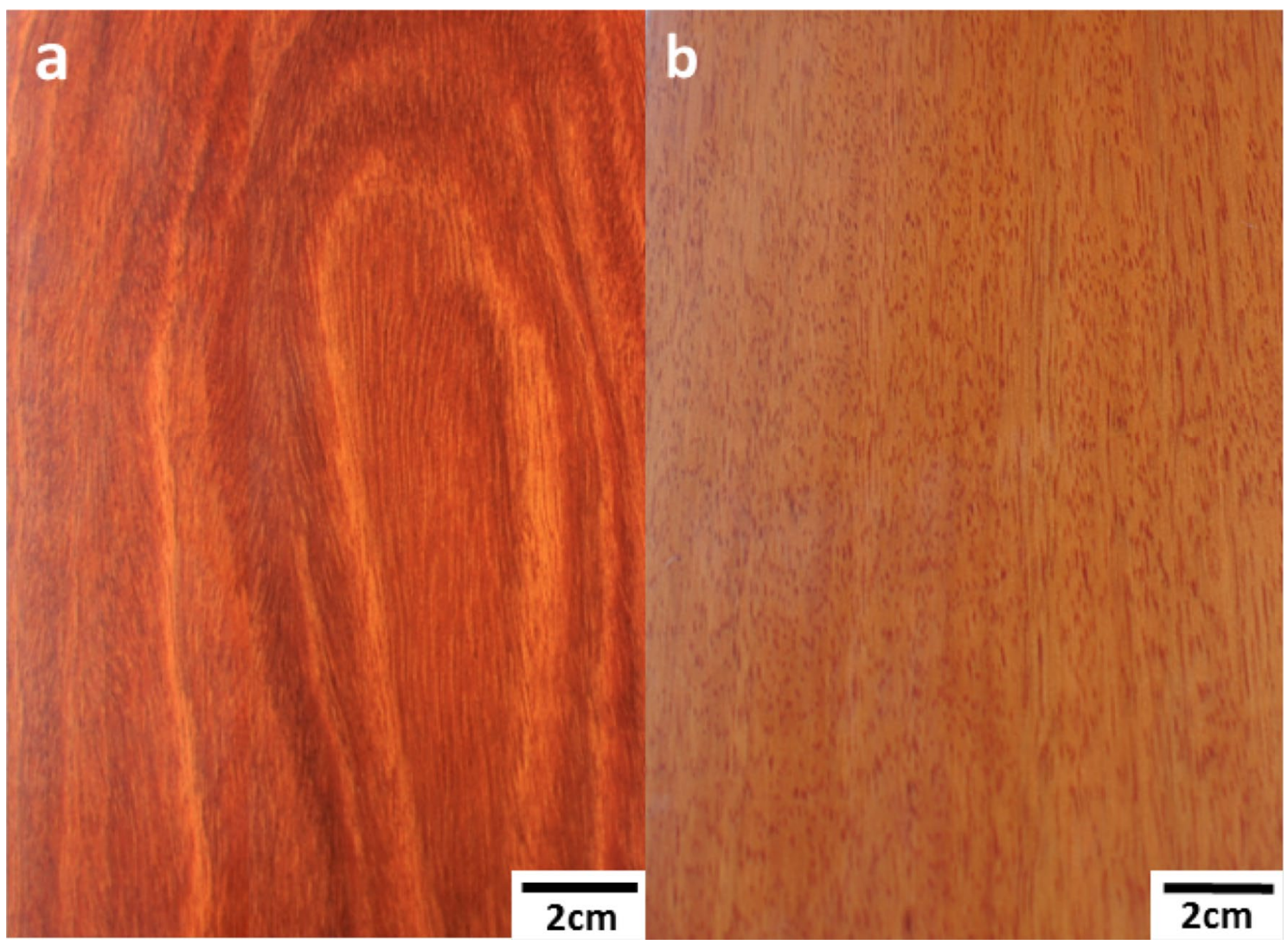

Fig. 1 The appearance images of solid wood floorings. a cumaru; b taun 

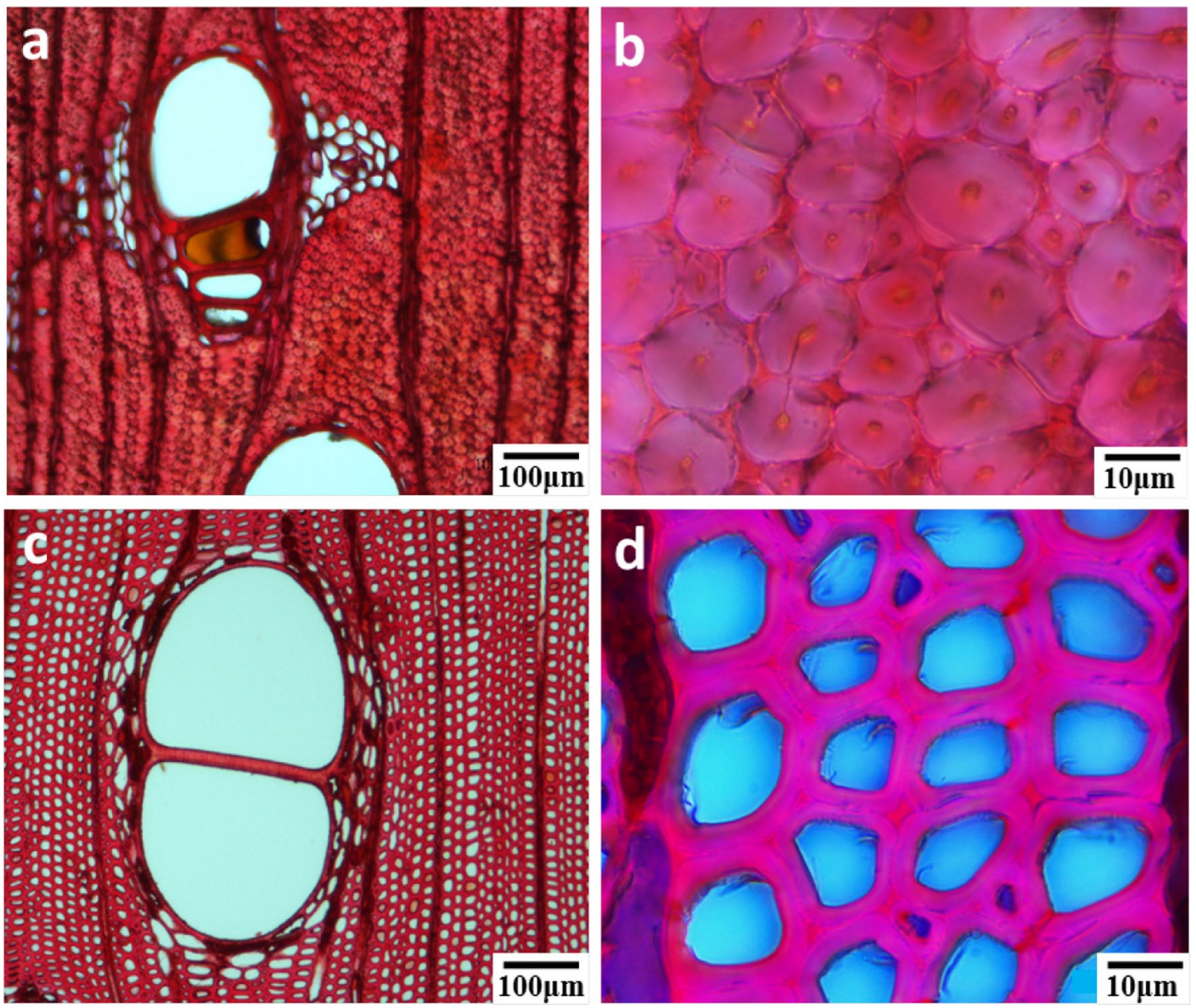

Fig. 2 Cross-section microstructure of cumaru and taun woods. a cumaru microstructure, $\mathbf{b}$ enlarged view of cumaru fiber cells, $\mathbf{c}$ taun microstructure, $\mathbf{d}$ enlarged view of taun fiber cells

had more cell wall substances. That is why it has a larger air-dry density than that of taun wood.

\section{Cell wall MFA analysis}

MFA is a microscopic characterization of wood cell wall structure. It is an important factor influencing the physical and mechanical properties of woods $[17,18]$. The X-ray diffraction patterns of samples from the two solid wood floorings are shown in Fig. 3. As shown in Fig. 3, the MFA of taun was different from that of cumaru. The MFA of all samples of the two kinds of woods were calculated by the $0.6 \mathrm{~T}$ method, and $11.7^{\circ}$ was obtained for the mean MFA of cumaru and $13.4^{\circ}$ for the mean MFA of taun. Variance analysis in Table 2 showed that the MFA of taun was significantly different from that of cumaru at the level of 0.05 . In addition to a larger MFA of cumaru wood than taun wood, the range of variation of MFA values of all samples of cumaru was smaller than that of taun. The standard deviation of MFA of taun was about twice of that of cumaru, and

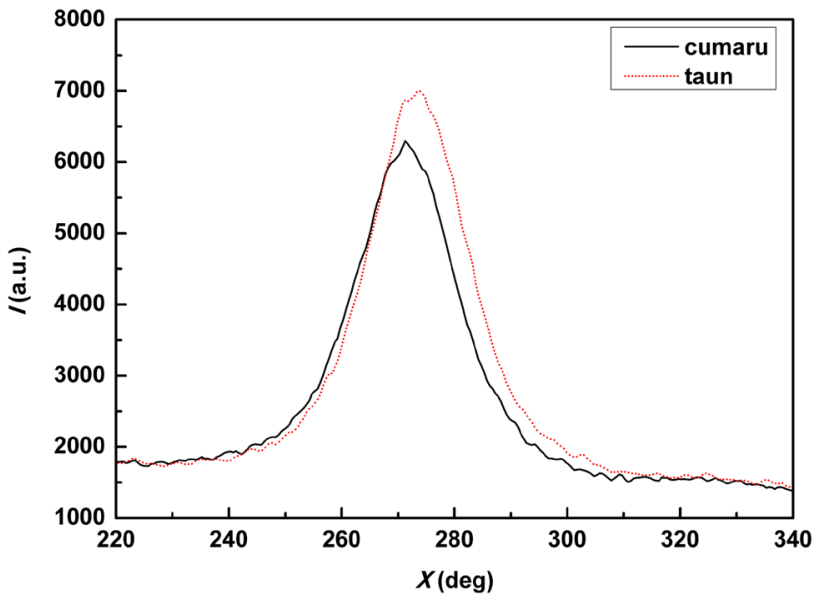

Fig. 3 X-ray diffraction spectrum during MFA test of cumaru and taun woods (representative spectrum from 25 samples, respectively) 
its coefficient of variation was larger than that of cumaru, as shown in Table 1. Therefore, it can be concluded that the texture of solid cumaru wood flooring is more uniform than that of taun wood flooring.

MFA is one of the most important factors affecting wood air-shrinkage and mechanical properties. The axial shrinkage of wood is positively correlated with MFA $[19,20]$. The MFA of cumaru was smaller than that of taun, indicating that its shrinkage was smaller than that of taun, the dimensional stability of cumaru wood flooring was better than that of taun, not prone to off-seam or warpage deformation. Studies on the macroscopic mechanical properties of the same batch of solid woods [3] showed that taun wood flooring with large cell wall MFA had low mechanical properties, while the cumaru wood flooring with superior mechanical properties had low cell wall MFA. Thus, it could be concluded that the cell wall MFA of the two wood floorings was negatively correlated with their macroscopic mechanical properties, which were consistent with the previous results that the smaller the MFA is, the better the longitudinal mechanical properties are [21].

\section{The cellulose crystallinity analysis}

Cellulose, as the wood cell wall skeleton material, is mainly divided into crystalline region and non-crystalline region. The crystallinity is a characterization of the proportion of crystalline regions of cellulose. The X-ray diffraction patterns of the taun and cumaru wood samples obtained by X-ray diffractometry are shown in Fig. 4. As seen from the figure, there were 3 diffraction peaks at $2 \theta$ of $16^{\circ}, 22.5^{\circ}$ and $35^{\circ}$ for the 2 wood floorings, corresponding to the (101), (002) and (040) crystal faces, respectively. There was a maximum peak value of (002) diffraction at $2 \theta=22.5^{\circ}$, and a minimum peak value

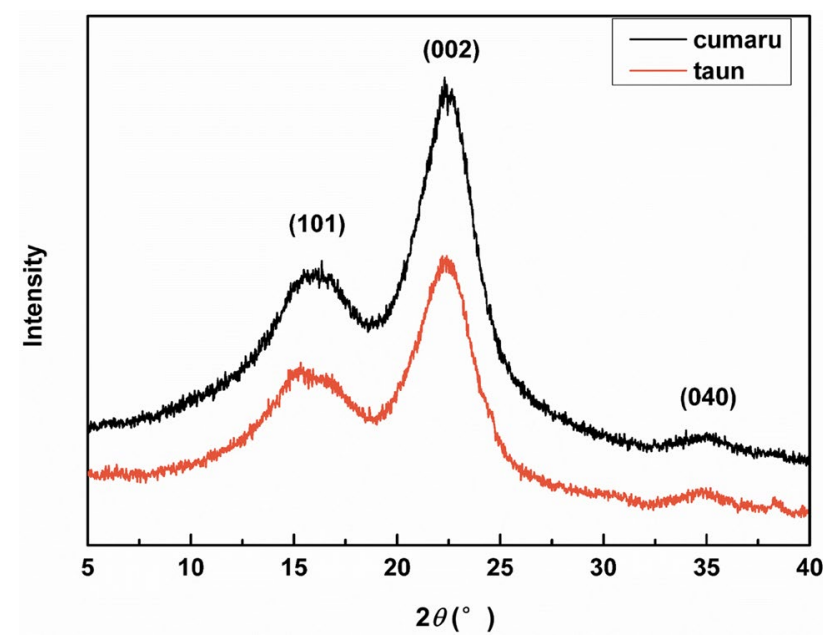

Fig. 4 X-ray diffraction chart of cumaru and taun woods (representative spectrum from 5 samples, respectively) at $2 \theta=18^{\circ}$. The X-ray diffraction patterns of taun and cumaru were basically similar, indicating that the unit cell of the crystalline part of cellulose of two wood species was the same, but the peak intensity of cumaru at the peak position $2 \theta=22.5^{\circ}$ was significantly higher than that of taun, indicating that the degree of crystallinity of cell wall cellulose of cumaru wood was greater than that of taun wood. In this paper, by calculation with the empirical method presented by Segal et al. [11], the relative crystallinity of cumaru wood was $54.0 \%$, while the relative crystallinity of taun was $50.8 \%$. The analysis of variance showed that crystallinity of taun was significantly different from that of cumaru at the level of 0.05 , as shown in Tables 1 and 2 .

Studies have shown that the crystallinity can reflect the physical and mechanical properties of woods to some extent. The larger the crystallinity of wood, the better the wood dimensional stability, mainly because the greater the crystalline crystallinity and the crystalline region, the closer the binding between the fibers, the harder for the water molecules to enter the cellulose molecular chains, and the larger crystalline region is more tightly constrained on the amorphous region, reducing their capacity of dry shrinkage and wet expansion and increasing the dimensional stability [22]. The larger the crystallinity of the wood, the better the mechanical properties of the wood, because highly ordered crystalline structure can improve the longitudinal strength and rigidity of wood, that is, the larger the cellulose crystallinity and crystalline region, the higher the modulus of rupture of cellulose and fiber tensile strength [23, 24]. Studies have shown that the dimensional stability and mechanical properties of cumaru solid wood flooring are better than that of taun solid wood flooring [3, 4], and the crystallinity of cumaru woods is higher than that of taun woods, which indicates that the cell wall cellulose crystallinity is another important factor influencing the physical and mechanical properties.

\section{Cell wall chemical composition analysis}

Wood cell wall is mainly composed of three kinds of polymers: cellulose, hemicellulose and lignin. In addition, wood also contains a small amount of extractive deposited on the cell wall or filled in the cell lumens. The chemical compositions of the cell walls of cumaru and taun wood floorings were tested according to Chinese national standards, and the results are shown in Table 3. As seen from the table, the chemical compositions of the cell walls of cumaru and taun

Table 3 Chemical compositions of cumaru and taun woods

\begin{tabular}{lcccc}
\hline Species & Extractive/\% & Lignin/\% & Holocellulose/\% & a-cellulose/\% \\
\hline cumaru & $7.85 \pm 0.38$ & $23.4 \pm 1.07$ & $64.3 \pm 0.21$ & $53.0 \pm 0.32$ \\
taun & $3.94 \pm 0.66$ & $22.0 \pm 0.37$ & $64.8 \pm 0.37$ & $48.2 \pm 0.16$ \\
\hline
\end{tabular}


were different. The holocellulose contents of cumaru and taun were 64.3 and $64.8 \%$, respectively, without great difference. But cumaru had a content of $\alpha$-cellulose of $53.0 \%$ and a lignin content of $23.4 \%$, both slightly higher than those of taun (content of $\alpha$-cellulose of $48.2 \%$ and lignin content of $22.0 \%$, respectively). In addition, the biggest difference in the cell wall chemical compositions between them was the content of extractive. With high content of extractive for cumaru (up to $7.85 \%$ ) and lower content of extractive for taun (only 3.94\%), the content of extractive of the former was about twice of that of the latter.

The content of chemical compositions and structural features of cell wall will affect the physical and mechanical properties of woods [25]. For example, the extractive deposited on the cell wall or filled in cell lumen will produce a significant effect on wood strength and permeability [18]. By comparing the chemical compositions of cumaru and taun wood floorings, it can be concluded that the holocellulose does not produce a decisive role in their physical and mechanical properties. The contents of $\alpha$-cellulose and lignin of cell walls of cumaru woods are higher than those of taun woods, especially for its higher content of extractive. They both may jointly affect the physical and mechanical properties of cumaru. Studies have shown that, the lignin, located between cellulose fibers, mainly play a role of compression resistance, and its content has the greatest impact on the hardness of woods [25]. The studies on Sequoia sempervirens, Robinia pseudoacacia and other woods showed that, the impact strength and bending strength parallel to grain of wood increased with the increase in extractive content [18]. The content of extractive of cumaru is twice as that of taun, so it is inferred that the high content of extractive of cumaru is one of the important factors that its compression strength, bending strength, and impact strength are higher than those of taun [3].

\section{Conclusions}

In this paper, comparison was performed between imported cumaru and taun woods for their air-dry density, microstructure, MFA, crystallinity and cell wall chemical composition. The two kinds of woods both are used to manufacture solid wood floorings, and there is distinct difference in their mechanical properties. Results showed that the cumaru with better mechanical properties had larger air-dry density, thicker cell wall with almost no cell lumen, smaller MFA, larger cellulose crystallinity and higher contents of $\alpha$-cellulose, lignin and extractive. However, compared with the cumaru wood floorings, the taun wood flooring with poor mechanical properties had lower air-dry density, thinner cell wall and greater cell lumen, larger MFA, lower crystallinity and slightly lower contents of $\alpha$-cellulose and lignin and extractive. These results revealed the cell wall structures and chemical compositions that influence the mechanical properties of the two solid wood floorings at the levels of tissue cell and cell wall.

Acknowledgements Funded by National Natural Science Foundation of China (31370562), National Key Research and Development Project (2017YFD060020103).

\section{References}

1. PR Newswire (2015) Wood and laminate flooring market analysis by product (wood flooring, laminate flooring), by application (residential, commercial, industrial) and segment forecasts to 2020 report linker review. PR Newswire, US

2. Xu F (2008) Wood identification (in Chinese). Chemical Industry Press, Beijing

3. Wang YR, Ren HQ (2012) Comparative study the physical and mechanical properties of three kinds of solid floor wood (in Chinese). J Anhui Agric Univ 39:894-898

4. Wang YR, Ren HQ, Zhao RJ, Lv B (2012) Study on the property of shrinkage and swelling of three kinds of solid wood floor (in Chinese). Wood Process Mach 23:9-11

5. Cui QP, Ye CX, Yang X, Cai YM, Sheng JK (2015) Dimensional stability analysis on solid wood flooring for ground with heating system under simulated Indoor conditions (in Chinese). Guangdong For Sci Technol 31:71-74

6. Fei BH, Yu Y, Huang AM, Xing XT (2010) Progress in cell wall mechanics of wood (in Chinese). Chin Bull Life Sci 22:1173-1176

7. Gindl W, Gupta HS, Schöberl T, Lichtenegger HC, Fratzl P (2004) Mechanical properties of spruce wood cell walls by nanoindentation. Appl Phys A 79:2069-2073

8. Reiterer A, Lichtenegger H, Tschegg S, Fratzl P (1999) Experimental evidence for a mechanical function of the cellulose microfibril angle in wood cell walls. Philos Mag A 79:2173-2184

9. GB/T 1933 (2009) Method for determination of the density of wood (in Chinese). Timber of Standardization Administrator of China, Beijing, China, pp1-5

10. Wang YR, Leppänen K, Andersson S, Serimaa R, Ren HQ, Fei BH (2012) Studies on the nanostructure of the cell wall of bamboo using X-ray scattering. Wood Sci Technol 46:317-332

11. Li J (2003) Wood spectroscopy (in Chinese). Science Press, Beijing

12. GB/T 2677.10 (1995) Fibrous raw materials-determination of holocellulose (in Chinese). China Light Industry Association, Beijing, pp221-223

13. GB/T 744 (1989) Pulps-determination of $\alpha$-cellulose (in Chinese). China Light Industry, Beijing, pp 156-158

14. GB/T 2677.8 (1994) Fibrous raw materials-determination of acidinsoluble lignin (in Chinese). China Light Industry Association, Beijing, pp213-215

15. GB/T 2677.6 (1994) Fibrous raw materials-determination of solvent extractives (in Chinese). China Light Industry Association, Beijing, pp210-212

16. Lin CJ, Chihming C (2007) Relationships among selected wood properties of 20-year-old Taiwania (Taiwania cryptomerioides) trees. J Wood Sci 53:61-66

17. Barnett JR, Bonhan VA (2004) Cellulose microfibril angle in the cell wall of wood fiber. Biol Rev 79:461-472

18. Liu YX, Zhao GJ (2004) Materials of wood resources (in Chinese). China Forestry Publishing House, Beijing

19. Liu YM, Liu SQ (2011) Microfibril Angle, Basic density and longitudinal shrinkage of inclined angles in artificial leaned saplings 
of poplarI- '107' (Populus $\times$ euramericana) (in Chinese). Sci Silvae Sinicae 47:115-120

20. Yang LQ (2014) The influencing factor of timber dry shrinkage and the methods of decreasing timber drying crack (in Chinese). For Mach Woodwork Equip 42:30-35

21. Cave ID, Walker JCF (1994) Stiffness of wood in fast-grown plantation softwoods: the influence of microfibril angle. Forest Prod J 44:43-48

22. Shi JT, Ding XH, Zhang X, Chen L (2017) Comparison of characteristics of branch and truck of Cunninghamia lanceolata from natural secondary forest (in Chinese). J For Eng 2:20-24
23. Deng B, Yang WX, Fang SZ, Li XM (2014) Growth and properties of juvenile Cyclocarya paliurus, and their correlation analysis (in Chinese). J Nanjing For Univ Nat Sci Ed 38:113-117

24. Ding T, Gu L, Li T (2011) Influence of steam pressure on physical and mechanical properties of heat-treated Mongolian pine lumber. Eur J Wood Wood Prod 69:121-126

25. Wang CG, Jiang ZH, Fei BH, Yu Y, Zhang SY (2012) Effects of chemical components on longitudinal MOE and hardness of wood cell wall (in Chinese). J B For Univ 34:107-110 